\title{
Public perceptions and utilisation of traditional and modern medicines in relation to malaria in Korogwe District, Tanzania
}

\author{
G.M. MUBYAZI \\ Ubwari Research Station, P.O. Box 81 Muheza, Tanzania \\ E-mail addresses: gmmubyazi@yahoo.co.uk/mubyazig@hotmail.com
}

\begin{abstract}
This study was carried out in Korogwe district, Tanzania to determine the methods used by the local communities in the treatment of malaria. Information was collected using both qualitative and quantitative methods, targeting members of households, health workers, traditional health practitioners and retail antimalarial drug sellers. Self-medication for mild illnesses was common, as it was reported that people either drink juices made from boiled local plant leaves and stems or take tablets mainly from retail drug sellers. In some cases both local and modern drugs were used, starting with local herbs and then modern drugs when the illness condition worsened. People residing far from health facilities were the main users of local herbs, and most of them consulted traditional health practitioners. The latter and their clients associated convulsions and coma with evil spirits sent by jealousy people to the victims. It is concluded that changing people's beliefs and practice about certain illnesses is difficult. However, efforts such as well designed, implemented and sustained health education and community sensitisation packages should form an integral part of the health care delivery system.
\end{abstract}

Key words: malaria, self-medication, care-seeking, traditional medicine, Tanzania

\section{Introduction}

Tanzania ranks the third in sub-Saharan Africa with serious malaria problem after Nigeria and The Democratic Republic of Congo (de Savigny et al., 2004). About $90 \%$ of the 34.5 million Tanzania populations are at risk of malaria (Tami et al., 2004; de Savigny et al., 2004). This disease accounts for a third of all outpatient visits, a third of inpatient admissions, and a deaths among children-under five years of age admitted (Mutabingwa et al., 2001a,b). Generally, malaria contributes to about 16 million episodes per annum and 100,000-125,000 deaths in Tanzania (de Savigny et al., 2004). The World Health Organization (WHO) has been encouraging its member countries to understand the socio-cultural factors that have influence on community health seeking behaviour in relation to malaria. This would help in designing and implementing effective home management of malaria interventions (WHO 1986).

As in the rest of sub-Saharan Africa, evidence indicate that the use of traditional medicines in Tanzania has a long history, as it has been a common practice among indigenous populations even before the onset of western colonial rule (Malebo et al., 2002). Traditional medical practice was discouraged after the coming of German missionaries in the 1880s on ground that it was an evil attempt contrary to God's will. It was until 1964 when the government of Tanzania decided to revive, among other things, the respect of traditional practices including traditional medicines, especially for their role in rural areas. Thus, the Tanzanian government recognises the presence and importance of other health service providers who complement or provide an alternative (in some cases) to the public health service system, as long as their operations are ethical and legal (MoH 1997). As an immediate response to this government open policy, some observers have warned that increased liberalisation with limited regulation of the private medical practice apparently erodes the prospects of good medical practice in the country (Wyss'-et al., 1996).

Factors that trigger individual household to seek for health care are important to explore as they are important determinants of household health status (Schumann et al., 1994). Socio-cultural explanation of illness that overlaps with the symptoms of malaria has been reported from an anthropological study in Muheza District, Tanzania (Oberlander \& Elverdan, 2000). The authors reported that the local people believed that the cause of convulsions is bad luck but not attributed to the activities of any person (such as a sorcerer). On the other hand, home and selfmedication of common illnesses by lay people was found to be common in East Africa (Geissler et al., 2000). The latter authors define self-medication as a situation when a person treats himself or herself without directly involving another person, while home treatment is when one household member is involved in the treatment of another member within the household.

It has been established that more often than not the demand for health-care varies among socioeconomic classes (Berman et al., 1994; Schumann \& Mosley, 1994). In verification of this, a survey in Dar es Salaam by Wyss et al. (1996) found 
that the type and quantity of medical care used by an ill person was that poorest people consulted private health facilities less often than they did on government health service. This paper reports and discusses methods and findings from a study undertaken between April 1999 and April 2000 to assess, among other things, public perceptions and their health-care seeking behaviour with emphasis on malaria treatment in a multiethnic and malaria holoendemic district in northeast Tanzania.

\section{Materials and Methods}

\section{Study area}

The study was undertaken in Korogwe District $\left(5^{\circ} 00^{\prime} \mathrm{S}, 38^{\circ} 15^{\prime} \mathrm{E}\right)$ in north-eastern Tanzania. The mean annual rainfall is $1100 \mathrm{~mm}$ and the mean daily temperature is $26^{\circ} \mathrm{C}$. The main economic activity is small-scale farming, mainly of maize, cassava, rice, beans, and bananas, followed by retail business (District Council Comprehensive Health Plan, 2004). Most of the residents' houses have muddy walls, uncemented floors, and are roofed with either grass or palm tree leaves. Few houses are made of burnt muddy bricks and roofed with corrugated aluminium sheets. Malaria (a tracer disease in this study) was the most serious communicable disease.

\section{Sampling and data collection}

A multistage sampling approach was adopted in the selection of 30 villages for the study. From each village, 15 heads of households or their representatives (anyone who was left to take care of the homestead) were selected by adopting a simple random sampling method. In total 450 households were covered. A survey was made to cover 11 health facilities. These included a district government hospital, 5 private-forprofit and 5 private-not-for-profit (owned by faith organizations) dispensaries. A total of 442 exit patients and 42 health staff were interviewed. Of the health staff, 6 were working at the district hospital and were all members of the district health management team (DHMT), 32 were working at private for-profit health facilities, and 12 were working at private-not-for profit (voluntary) health facilities. A total of 24 focus group discussions (FGDs) sessions were held in 8 villages, whereby 216 village residents participated in the discussions.

Three FGDs in each village (including a group of women of childbearing age (15-49 years) and above, 2 groups of men ( 1 with men aged $18-34$ years and 1 with men aged $\geq 35$ years). FGDs were conducted separately for men and women and taking age into consideration to maximize freedom (confidence) of individuals. Each group consisted of 6-10 people as recommended (Smith \& Morrow, 1996). In addition, the survey covered 20 retail shopkeepers/kiosk dealers who were selling drugs in 20 villages. In the remaining 10 villages there were no any drug selling retail outlet. In addition, a total of 17 traditional health practitioners (who coincidently were found acting both as herbalists and witchdoctors) were approached for interview. Drug sellers were selected using a convenient sampling method while other types of respondents were selected by adopting a purposive sampling technique.

Data from households and retail drug sellers were collected using interview administered semistructured questionnaires. FGDs and key informants interviews with (health staff and traditional health practitioners) were conducted based on open-ended questionnaire guide prepared in advance. In addition, direct observations were done on events and things like types of housing and general living environment of the study populations as well as the availability of different brands of antimalarial drugs in the retail sources and other local herbs traditionally and currently used for the treatment of malaria.

\section{Results}

The majority of FGD participants (in 17 out of 24 FGDs) reported to have had experienced at least an episode of malaria in the preceding six months, and to have contacted formal health facilities. In all the 24 FGDs held, self-medication and home-based treatment using modern drugs bought mainly from retail market outlets (shops, drug stores, and kiosks) and local herbs were commonly practised for malaria treatment. This was most common when the people found it inconvenient to contact formal health facilities, especially when the facilities were far from their homes. The main local plant herbs reported to have been used included Azadiracta indica, Plectranthus barbacus, Artemisia afra, Ocimum suave and eucalyptus.

Traditional herbs were more often used when there was limited means to obtain alternative modern drugs or in case of treatment failure or due to side effects of such drugs. Nevertheless, some discussants pointed out that sometimes herbs were used in combination with modern drugs. Some people had a perception that it is more helpful to use traditional herbs even if they have received an effective modern drug.

Majority of the participants in 17/24 (71\%) FGDs were of the opinion that traditional health practitioners 
were also contacted by many village residents if someone such as a child had convulsion or if someone is in a state of coma while at home. The commonest belief was that convulsions were due to witchcraft.

Of the 20 drug sellers who were asked about the types of drugs that were frequently bought from their outlets, 18 (90\%) mentioned chloroquine, 14 (70\%) fansidar or metakelfin (sulfadoxine-pyrimethamine), and $5(20 \%)$ quinine (Table 1). Moreover, 8 (40\%) of the sellers were of the opinion that chloroquine and fansidar were proportionately more bought from their outlets because of their relative availability. Eighteen (90\%) of the drug sellers reported that children were the dominant group coming to buy antimalarial drugs at their outlets. However, children were just representing their caretakers (parents/relatives) who sent them on their behalf.

With regard to how often drug customers present prescriptions from authorized practitioners $9(45 \%)$
Poverty was pointed out as one of the major barriers to access to modern health services. Nearly all the FGD participants said that, people residing in remote rural areas, far from formal health facilities most often relied on traditional medicines than people in peri-urban and other areas closer to health facilities. In an attempt to justify a community concern about long walking distance to the nearest facility one participant in Magoma village (about $25 \mathrm{~km}$ from Korogwe town, the district capital) lamented: 'We can't pay for the bus fare and afford to pay for medical services at the district hospital." Concerning poverty, all the $17(100 \%)$ practitioners reported to have been consulted many times by malaria patients who could not pay for the medication. While 15/17 (88\%) confirmed to have seen them many times, the rest $(12 \%)$ reported to have seen them very rarely. Probed

Table 1: Antimalarial drugs bought by community members at retail shops/kiosks in Korogwe district

\begin{tabular}{lc}
\hline Type of antimalarial drug & $\begin{array}{c}\text { Number and percentage }(\%) \text { of shopkeepers who } \\
\text { responded }(\mathrm{n}=20)\end{array}$ \\
\hline Chloroquine & $18(90 \%)$ \\
Fansidar & $8(40 \%)$ \\
Metakelfin & $6(30 \%)$ \\
Quinine & $5(20 \%)$ \\
\hline
\end{tabular}

said to always have clients showing prescriptions. Five (25\%) had only seen few with prescriptions, whereas the rest could not remember. It was not clear to the sellers whether those who did not show prescriptions were fully knowledgeable of the standard treatment guidelines and doses for the drugs they buy. All the 20 drug sellers reported their experience that the majority of village residents contacted formal health facilities when they suffered from malaria. Interestingly, all the drug retailers considered antipyretics such as paracetamol as having antimalarial effect.

Of the 17 traditional health practitioners, $8(47 \%)$ associated convulsions and coma with superstitious powers. However, when they were asked on what they personally do when someone gets malaria, they reported to have had either been consulting formal health facilities or used locally identified herbs or buy some antimalarial drugs from a shop. further, they said that, such a person would be exempted from payment or would be given an alternative opportunity to pay in-kind (disposing things like chicken). A chicken was worth US\$ 3 during the study period.

Apart from many people consulting traditional health practitioners on malaria related problems, 8 / $17(47 \%)$ practitioners were of the experience that the majority of local people contacted formal health facilities but end up finding the last resort from them because of their reliable services using traditional medicinal expertise. Traditional healers were found to have knowledge on the causes of malaria and reasons for higher prevalence of malaria at community level. They associated high malaria prevalence with high mosquito densities $7 / 17$ (41.2\%), low community use of preventive items such as bednets $3 / 17(18 \%)$, low community knowledge of preventive measures $7 / 17(40 \%)$, and negligence of many people to adopt preventive measures 5/17 (29\%) (Table 2). 
Table 2: Reasons reported by traditional health practitioners as to why malaria prevails at community level

Reason

Presence of high mosquito densities

Low community knowledge of preventive measures

Negligence by community members to take measures

Poverty, hence low community use of items such as bed nets
Number and percentage (\%) of respondents

$7(41.2 \%)$
$7(40 \%)$
$5(29 \%)$
$3(18 \%)$

A total of 301 (67.2\%) household respondents reported to have known some of their village mates who previously had failed to seek for medical care from formal health facilities due to lack of money. However, the majority $(70.3 \%)$ of the community members mostly sought care from formal health facilities, besides use of traditional medicines as their first aid at home or as an alternative after the treatment from health facilities seemed to fail. Local herbs like those reported by other types of respondents were identified to have been in use for malaria treatment (almost 90\% of the respondents). About a half of the household respondents also said that they have been using antipyretics such as paracetamol for malaria treatment. The drugs used were reported to have been obtained from retail outlets such as shops and kiosks available in their localities. A few household respondents associated convulsions with witcheraft (data not shown).

Of all the exit patients interviewed, 429 (97\%) reported to have had suffered and sought treatment from formal (mainly public) health facilities during the preceding six months, and they all accepted to have been self-treating with drugs bought from commercial sources as an alternative option when they decided not to attend at health facilities or when they were directed by health facility staff to buy drugs on their own.

All the health workers ranked malaria as number one cause of morbidity and mortality in the district. A little more than half of all the respondents acknowledged that traditional practices have a substantial influence on people's choice of health care providers. This was more common when an illness was associated with witchcraft. As a result, there were some delays in reporting to formal health facilities, sometimes, only when the conditions have worsened. Probed further to justify how they came to know this, the respondents said that they normally got informed either by the patients themselves or by people who knew them, and that it has been the tradition of the population to rely heavily on local herbs. Poverty was perceived by $42 / 44$ (96\%) of private health workers and all the 6 DHMT staff as a deterrent to a considerable proportion of population to contact formal health facilities where health-care user charges were implemented. Supporting their argument, they stated to have been meeting people complaining to have no money to pay for health-care charges. Some staff reported that alcoholism among men perpetuated poverty in their households.

\section{Discussion}

Poverty has discouraged a considerable proportion of people from utilising formal health services, particularly where patients were required to pay user charges. The greatly affected people are those living in peripheral rural areas, from formal health facilities. These may also include those who either fail to pay for the medical services after they had paid for the transport cost. In some cases most of them would decide to remain at home and have alternative medication. On the other hand, consultation with traditional health practitioners seems to have no direct link with household's poverty in this case, but to a great extent, the belief about certain illness conditions could be effectively dealt with by such practitioners. For example, comparing the cost per dose of chloroquine to an adult person (10 tablets) that was by then the Tanzanian first-line antimalarial drug, and the cost of other household properties (e.g. chicken) paid out to traditional practitioners, one can see that the decision to contact traditional health practitioners is not solely or necessarily driven by one's inability to pay per se. It might be due to household's perception of traditional versus modern medicines, if not due to their inaccessibility to cash. An important factor to consider is that the lack of cash does not necessarily imply that one is poor, as poverty indexes range from inaccessibility to cash and other material wealth that does not provide for one to access basic needs including food, shelter, clothing, and social services.

The findings of this study supports evidence from previous studies that self-medication is a common practice among communities of Tanzania (Alilio'-et 
al., 1995). Self-medication is practised without adequate supervision/monitoring to ensure compliance with the recommended diagnosis and treatment standards. Without strict rules to monitor drug selling practices, including the issue of counterfeit drugs and controlling importation channels and non-dispensation of expired drugs in commercial pharmaceutical outlets, it will remain a dream to recommend correct diagnoses and treatment in the health system. It will also be a dream that drug resistance trends will be reversed in the environment whereby health services are inadequately utilised and compliance with services is improved.

Although it may sound very interesting that allowing retail drug business to take part in drug distribution would increase access of drug to communities in need, it is not surprising seeing that the national health policy and drug regulations bodies have overlooked the low level of knowledge about proper drug storage and administration amongst the majority of the drug vendors/retail sellers. There is also an overlook that demand driven incentives are likely to persist in the retail drug business. This is due to the fact that most drug traders would not bother about what consequences happen to their customers after drug use apart from their personal motive of maximising profit even from people who are willing and able to pay for sub-standard doses. This means there is an urgent need for the government to review the liberal drug market policy, formalise guidelines and enforce laws governing the drug storage and dispensing qualifications and behaviours of people interested in entering into drug trade business.

It is good to appreciate that considering the general low knowledge about malaria facing endemic countries, changing people's beliefs and practice on antimalarial drugs'- be it traditional or modern is necessary. But it is possible if tireless efforts and systematic strategies were organised to educate and sensitise the community on the importance of appropriate malaria diagnoses and treatment with the recommended drugs including observation of the standard drug dosage. Health care providers, at formal and informal drug outlets should also be encouraged and motivated to provide correct information to their clients about the use of the drugs, and the language used should be clearly understood to the drug users. Communities are likely to over-rely on traditional medicines in the absence of right information in the right place and at the right time on one hand, and absence of appropriate drug at the right place and in the right time.

\section{Acknowledgements}

Many thanks to Whitney Schott, Jose Ravano, Lynne Franco Miller and Ellen Bobronnikov for their technical assistance from the design and ultimate conduction of the study. I am grateful to Vivien Barongo for her comments on the earlier version of the manuscript. Dr. Andrew Y. Kitua, Director General, National Institute for Medical Research is thanked for granting permission to publish this paper. The Tanzania Medical Research Coordinating Committee is also thanked for granting ethics clearance. This study received financial assistance from the United States Agency for International Development through Abt Associates Inc. under the Partners for Health Reforms Project.

\section{References}

Alilio, M.S., Kamugisha, M.L., Msuya, F.H., Massaga, J.J., Salum, F.M., \& Njunwa, K.J. (1997) Availability and utilisation of antimalarial drugs at community level in Same district of north eastern Tanzania. Malaria and Infectious Diseases in Africa 6, 8-12.

Berman, P., Kendall, C. \& Bhattacharrya, K. (1994) The household production of health: integrating social science perspectives on micro-level health determinants. Social Science and Medicine 38, 205-215.

De Savigny, D., Mayombana, C., Mwageni, E., Masanja, H., Minja, A., Mkilindi, Y., Mbuya, C., Kasale, H. \& Reid, G. (2004). Care-seeking patterns for fatal malaria in Tanzania. Malaria Journal 3, 27.

Geissler, P.W., Nkes, K., Prince, R.J., Achieng'Odhiambo, R., Aagaard-Hansen, J. \& Ouma, J.H. (2000) Children and medicines: selftreatment of common illnesses among Luo schoolchildren in western Kenya. Social Science and Medicine 50, 1771-1783.

Malebo, H.M., Mhame, P.P., Mapunda, A., MalecelaLazaro, M.N. \& Kitua, A.Y. (2002) The Pharmacological Potential of Medicinal Plants Traditionally Used by Households in Kagera Region for the Treatment of Malaria and Other Diseases. Proceedings of Annual Health Sector Reform Laboratory Conference held in Bukoba, Tanzania in June 2002.

Mnyika, K.S., Kilewo, J.Z.J. \& Kabalimu, T.K. (1995) Self-medication with antimalarial drugs in Dares-Salaam. Tropical and Geographical Medicine $47,32-34$. 
MoH (1997) Report of the Health Sector Reform Programme of Work 1998-2001. Ministry of Health, Dar es Salaam, Tanzania.

MoH (1999). /Health Statistics Abstracts. Ministry of Health, Dar es Salaam, Tanzania.

Mutabingwa, T., Nzila, A., Mberu, E., Nduati, E., Winstanley, P., Hills, E. \& Watkins, W. (2001a) Chlorproguanil-dapsone for treatment of drug resistant falciparum malaria in Tanzania. The Lancet 358, 1218-1223.

Mutabingwa, T., Nzila, A., Nduati, E., Winstanley, P. , Hills, E. \& Watkins. W. (2001b) A trial of proguanil-dapsone in comparison with sulfadoxine pyrimethamine for the clearance of Plasmodium falciparum infections in Tanzania. Transactions of the Royal Society of Tropical Medicine and Hygiene 95, 433-438.

Oberlander, L. \& Elverdan, B. (2000) Malaria in the United Republic of Tanzania: cultural considerations and health seeking behaviour.
Bulletin of World Health Organization 78, 13521357.

Schumann, D.A. \& Mosley, W.H. (1994) The household production of health: introduction. Social Science and Medicine 38, 201-204.

Tami, A., Mubyazi, G., Talbert, A., Mshinda, H., Duchon, S. \& Lengeler, C. (2004). Evaluation of Olyset insecticide treated nets distributed seven years previously in Tanzania. Malaria Journal 3, 19.

WHO (1986) Investing in Health Research and Development: A Report of the Ad hoc Committee on Health Research and Development Relating to Future Interventions. TDR/Gen/96.1, Geneva, Switzerland

Wyss, K., Whiting, D., Kilima, P., McLarty, D.G., Mtasiwa, D., Tanner, M. \& Lorenz, N. (1996) Utilization of government and private health services in Dar es Salaam. East African Medical Journal 73, 357-363. 